ORIGINAL RESEARCH ARTICLE

\title{
Press Start: the value of an online student-led, peer-reviewed game studies journal
}

\author{
Matthew Barr* \\ School of Humanities, University of Glasgow, Glasgow, United Kingdom \\ (Received 10 July 2017; final version received 05 November 2017)
}

\begin{abstract}
In this article, an online student journal is described, and the ways in which student participants value the journal are discussed. Press Start is a peer-reviewed international journal of game studies, which aims to publish the best student work related to the academic study of video games. Content analysis of qualitative survey data $(n=29)$ provides insights into what students value about the journal, revealing six broad themes: community and support, inclusiveness and accessibility, the published research, feedback from peer review, experience of conducting peer review and the opportunity to publish. The article concludes by suggesting that engagement with online student journals should not be limited in terms of geography or the level of study, unless there are robust pedagogical reasons for doing so.
\end{abstract}

Keywords: online journals; Facebook groups; student engagement; publishing; peer review; game studies

\section{Introduction}

While Walkington and Jenkins (2008) observe that 2008 marked the beginning of a 'new wave' of undergraduate research journals, such initiatives may be traced back to much further. Charlesworth and Foster (1996) describe the use of an undergraduate journal to 'empower' physical geography students and assess their work, starting in the late 1980s. Such an approach remains typical of the way in which student research journals operate. These journals tend to function at a departmental or an institutional level (Walkington 2014), and typically serve as showcases for student work, or as part of an internal assessment exercise, rather than as a venue for disseminating research. Furthermore, most student research journals are aimed exclusively at a particular level of student - either undergraduate or postgraduate.

Limiting the scope of student journals on the basis of institution or the level of study has obvious practical benefits and is often necessary if the journal is to be used as a means of formal assessment. However, the journal described here is unconventional in a number of ways, not least in its international focus and its engagement with students at all levels. The journal's international scope and the collaborative processes that underpin its operation are functions of the underlying technology: without access to a robust online peer review system and supporting social media technologies, such a project could not be undertaken.

*Corresponding author. Email: Matthew.Barr@glasgow.ac.uk

Research in Learning Technology 2017. @ 2017 M. Barr. Research in Learning Technology is the journal of the Association for Learning Technology (ALT), a UK-based professional and scholarly society and membership organisation. ALT is registered charity number 1063519 http://www.alt.ac.uk/. This is an Open Access article distributed under the terms of the Creative Commons Attribution 4.0 International License (http://creativecommons.org/licenses/by/4.0/), allowing third parties to copy and redistribute the material in any medium or format and to remix, transform, and build upon the material for any purpose, even commercially, provided the original work is properly cited and states its license. 


\section{Barr}

While the positive impact of student journals has been documented to a degree (Mariani et al., 2013; Hurkett et al., 2013; Caprio, 2014; Stone et al., 2016), of student journals are not universally accepted, and the existence of such publications may also be seen to have a negative impact or cost. Gilbert (2004) makes a strong case against such initiatives, on the basis that the existence of undergraduate journals increases pressure on students, who may feel that they must publish in order to proceed to postgraduate study. Gilbert also suggests that such journals can only increase 'the stress on faculty'. This concern is echoed in the findings of Schofield and Burton (2015) where, in an otherwise positive analysis of the value of staff-student collaboration on a journal, finding time to support the project is identified as the 'only real concern' shown by staff. Available time - of both staff and students is also identified as a constraint by Lambert and Metcalfe (2009), who suggest that 'limited time, knowledge, encouragement, skills, and resources can all conspire to discourage undergraduate participation in research'. Waye and Simpson (2016) describe the impacts of a student journal under three broad categories: lateral, direct and indirect impacts. While many of these impacts are positive, the lateral impacts identified by Waye and Simpson include a number of costs, including time. Extending Gilbert's earlier point about placing undue pressure on students, Waye and Simpson suggest that student journals may also exert 'pressure on undergraduate instructors to supervise students in a research project and coach it to publication standards'. Finally, Gilbert suggests that an undergraduate journal is destined to become one of 'not-ready-for-prime-time studies' - the best research, he argues, should be published in a 'real' journal, regardless of the level at which the research was undertaken. These are all valid concerns; however, there are clear advantages for students publishing their research and there exist means of addressing - if not entirely overcoming - these concerns, some of which will be outlined here. The purpose of this study, then, is to determine whether the benefits of running a student journal outweigh the perceived disadvantages and costs.

\section{The Press Start journal and Facebook group}

Press Start (http://press-start.gla.ac.uk) is a student-led, peer-reviewed journal that publishes student work related to the academic study of video games. It was founded in 2014 with two primary aims: to provide students with opportunities to develop their writing skills by submitting or peer reviewing work and to allow students to gain experience of working together to deliver a project with an international profile. The journal also provides students studying games with a venue for publishing high-quality work that might otherwise have gone unnoticed. Students with an academic interest in games can often feel isolated if they are based in a department that does not routinely study them, and this is often the case. In the absence of dedicated game studies departments - and, indeed, dedicated game studies scholars - student work on games is typically found in isolated pockets within subject areas that range from English literature to psychology. Press Start differs from other student journal initiatives in that it is intended to fill the gap left by the lack of established institutional support and expertise in games studies. While a tutor or lecturer in a more established discipline will almost certainly be aware of publishing opportunities for aspiring scholars in their field, it is less likely that they will be able to direct their students towards suitable venues in the unfamiliar and nascent discipline of game studies. Press Start may be considered a 'grassroots' publication in this sense. It is run entirely by students and 
awareness of its existence has spread largely by word of mouth such that potential authors discover the journal through their peers rather than their tutors. The Press Start Facebook group, ${ }^{1}$ for example, comprises more than 350 members, extending the journal's reach and offering opportunities for engagement beyond individual departments or institutions.

As stated above, Press Start is run entirely by students. The authors, the reviewers and the editorial board are all currently engaged in the study of games, at every level, from undergraduate to $\mathrm{PhD}$. Recent graduates are also permitted to submit their work for publication, acknowledging that recent graduates considering further study would stand to benefit from the experience of publishing their work. This arrangement is also intended to support the publication of work produced by students at the end of their final year, such as dissertations, which the authors might otherwise lack the time to prepare for peer review.

The journal has also run a number of innovative initiatives. A recent online AMA ('Ask Me Anything') with an experienced game studies academic provided students with valuable insights into giving (and dealing with) peer feedback. The AMA was conducted within the journal's Facebook group and facilitated by the editor, remotely from the academic answering questions, and included students from across the globe. Such endeavours are only made possible by embracing suitable online technology, and the Facebook group is very much used as an extension of the digital tools provided by the journal software (Open Journal Systems ${ }^{2}$ ). Another initiative has paired games development students - who often prefer coding to academic writing - with confident writers, such as students from the humanities. The idea is that new collaborations are formed and games development students are inspired to engage with the wider game studies community.

A number of measures are in place to help ensure the sustainability of the journal and continued availability of published work. Articles are published under a Creative Commons Attribution License and copyright for articles is retained by the authors. This means that students are free to post their work on their own sites or to services such as Academia.edu. The journal is indexed by Google Scholar, WorldCat, EBSCO and others, ensuring discoverability of students' work.

Press Start also provides immediate open access to its content based on the principle that making research freely available to the public supports a greater global exchange of knowledge and also improves the visibility of students' work. In accordance with the guidelines laid down by the Budapest Open Access Initiative (2012), ${ }^{3}$ articles are freely available via the Internet, permitting any users to read, download, copy, distribute, print, search or link to the full texts. Furthermore, the journal utilises a distributed archiving system (Lots of Copies Keep Stuff Safe - LOCKSS ${ }^{4}$ ) that permits libraries to create permanent archives of the journal for purposes of preservation. This approach also ensures that the work is available in the long term, and not only through the journal's website.

The journal also features a strong editorial board, meaning that responsibility for and knowledge of - the running of the journal is distributed. This is especially important for Press Start given the transient nature of the board members' student status. At present, board membership is reviewed on an annual basis, and no individual is permitted to sit on the board for more than 2 years. This limit is intended to ensure

${ }^{1}$ https://www.facebook.com/groups/PressStartJournal/

${ }^{2}$ https://pkp.sfu.ca/ojs/

${ }^{3}$ http://www.budapestopenaccessinitiative.org/boai-10-recommendations

${ }^{4}$ https://www.lockss.org/ 


\section{Barr}

that a great number of suitably dedicated students are afforded the opportunity to gain this valuable experience.

\section{Method}

To evaluate the impact of the journal on the students involved, an online survey was conducted and a link was posted to the Press Start Facebook group, soliciting 29 responses from the journal community (representing a response rate of $7.4 \%$, based on a total Facebook group membership of 392). A link to the survey was also posted on the journal's Twitter account; however, as a private group devoted to the journal, the Facebook group arguably represents the most direct means of recruiting participants familiar with its operation. Furthermore, Facebook remains the world's most popular social media site, used by $83 \%$ of online women and $75 \%$ of online men (Showers 2017). Thus, it is not thought that using the Facebook group to recruit participants would exclude any section of the community. In addition to collecting demographic information, the survey presented a simple, open-ended question: 'What do you value about Press Start?' The responses to this question were then analysed by means of classical content analysis (Bauer 2000, p. 149; Marvasti 2004, p. 94). The data set is relatively small, but NVivo qualitative data analysis software was used to facilitate content analysis and identify themes.

As noted by Santiago-Delefosse et al. (2016), notions of rigour in the analysis of qualitative data may be connected with insightfulness or with threats to reliability and validity. While the analysis of survey data below offers insight into what students value about the online journal, questions relating to the reliability and validity of qualitative data - its credibility - may be addressed by means of triangulation. Kuper, Lingard, and Levinson (2008) define triangulation as 'multiple methods or perspectives to help produce a more comprehensive set of findings', suggesting that such approaches can 'increase insight into a phenomenon'. Twining et al. (2017) note that a range of triangulation methods are found in the literature, and the simple method used here combined data triangulation ('using data from different participants or at different times') and method triangulation ('using multiple methods to collect data'). Following content analysis of the main survey data, members of the online journal community were asked to complete a subsequent survey, presented as a poll wherein respondents could indicate what they valued about Press Start. Poll options were derived from the six themes identified in the survey data and the question was stated as 'Which of the following do you value about Press Start?' (see Figure 4). Respondents could select as many options as they saw fit, and the poll attracted 23 responses $(5.5 \%$ response rate, based on Facebook group membership of 392).

\section{Results}

Broad demographic data were collected in order to develop an understanding of the nature of the Press Start community. In terms of gender, the survey offered a range of options ('female', 'male', 'transgender', 'other' and 'prefer not to say'), but only the female and male options were selected. Of the survey respondents, $39.7 \%$ were females. The mean age of the respondents was 28.7 years, with a median of 28 years.

Based on the survey data, the journal community is dominated by postgraduate students (see Figure 1). 


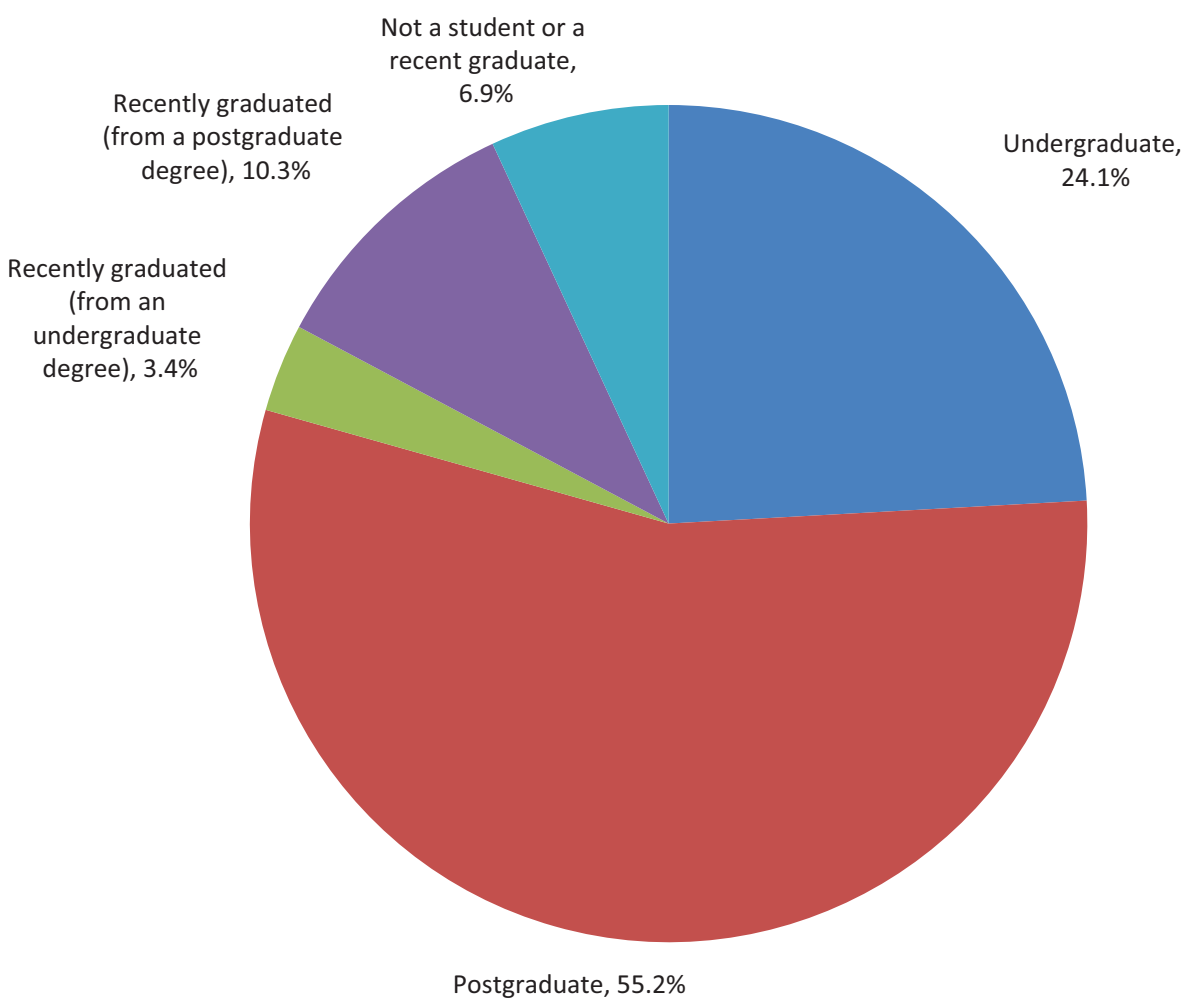

Figure 1. Survey respondents' level of study.

It is perhaps unsurprising to see such a high proportion $(55.2 \%)$ of postgraduate students and recently graduated postgrads $(10.3 \%)$ involved in the journal - independent research and publication is of relatively little concern to most undergraduates. However, it is encouraging to see that about a quarter of the community are undergraduates, as the journal is intended to provide students at all levels with an opportunity to publish or engage in peer review.

In response to the question, 'Are (or were) your studies based within a dedicated game studies department, subject area or institute?', a surprisingly high proportion of respondents $(37.9 \%)$ indicated that they were part of a game studies department. While it is perhaps inevitable that those students fortunate enough to have found a home within departments dedicated to their subject area would be most aware of Press Start, this was not entirely the intention in setting up the journal. One of the stated aims was to establish a community and publication venue for students working on games-related topics outside of dedicated departments - those comprising the remaining $62.1 \%$.

Survey respondents were asked if they had published previously with the journal or if they had acted as a reviewer. The majority of respondents $(82.8 \%)$ indicated that they had not previously published in the journal, while a smaller majority $(58.6 \%)$ replied they had not acted as a reviewer. This is in line with expectations: clearly the pool of students who have submitted a paper and seen it through peer review is likely to be smaller than the pool of reviewers. The journal is set up to ensure that as many students as possible gain experience of peer review, not least by insisting on a minimum of three peer reviewers per submitted manuscript. Editorial board members are also encouraged to assign a mixture of experienced and inexperienced reviewers 


\section{Barr}

when taking a manuscript through the peer review process, to ensure that everyone who wishes to do so has the opportunity to develop the necessary skills. Furthermore, taking part in peer review is a rather less daunting undertaking than preparing and submitting a piece of one's own work for peer review, especially where the potential authors are relatively inexperienced in academic publishing. Thus, working as a reviewer is a potentially attractive first step for many students. The remaining proportion of the community, then, comprises those students with an interest in Press Start - readers of the journal and members of the Facebook group - who have yet to engage more actively.

Finally, $82.8 \%$ of respondents stated that they were interested in pursuing an academic career, for example, as a researcher or lecturer. In this regard, the Press Start community is far from typical of the wider student body, but it is to be expected that students already engaged in academic publishing might harbour academic ambitions. More striking is the proportion of the community with experience of academic publishing beyond Press Start, with $62.1 \%$ of respondents stating that they had previously presented a conference paper, published a journal article or reviewed for a conference or journal. The fact that such a high proportion of the Press Start community has gained this experience elsewhere suggests that the journal is not necessarily acting as a stepping stone to academia, as might be expected. Instead, students may view the journal as one of several routes to publication; however, this is an issue that could be explored in more detail. It may be that, for many of these respondents, their involvement with Press Start predated other publishing endeavours and actually helped prepare them for subsequent publication opportunities. Or, as the analysis of the open-ended question below suggests, students may value their engagement with Press Start for reasons other than publishing. It may be, for example, that students with a particular focus on developing an academic career have already sought out potential publishing opportunities, but value the support and feedback they gain from the online Press Start community, in particular.

The ways in which Press Start has had a positive impact on the students involved are revealed in the survey data, and the themes that emerged from content analysis of the open-ended question about what they value are considered here.

\section{Community and support}

Respondents overwhelmingly suggested that the community that had developed around Press Start was what they valued most about the journal. Examples of responses included the following: 'Excellent and supportive community' (postgraduate, male, age 42); 'Members [of the community] are helpful and friendly' (postgraduate, female, age 25); 'The bottom-up academic community is very sympathetic' (postgraduate, male, age 28). This reference to a 'bottom-up' community arguably not only speaks to the ideas of inclusiveness and accessibility discussed below but also aligns with the idea that the journal is a 'grassroots' initiative - the Press Start community has evolved with little intervention from teaching staff. The notion that Press Start is a 'grassroots' operation is further supported by the finding that a large proportion of respondents discovered the journal by word of mouth (37.9\%) or Facebook (24.1\%) (see Figure 2).

Again touching on inclusiveness, one respondent suggested that the supportive community was a factor in assuring the quality of the published work: 


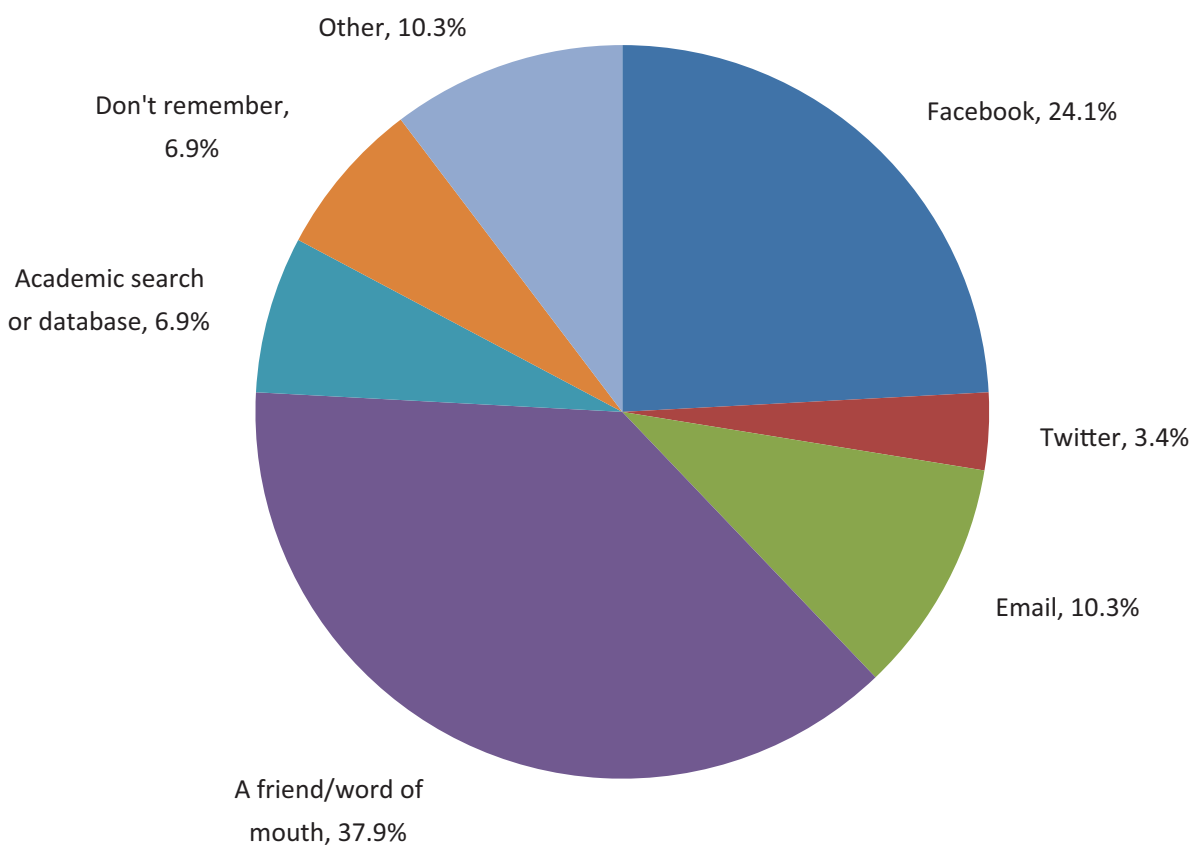

Figure 2. Survey responses to the question 'How did you find out about Press Start?'.

I value and respect Press Start's focus on community, which fosters a space for mentorship and learning about academic processes and expectations through peers and established (but accessible and supportive) scholars alike. It seems to me that the high quality of submissions and publications is maintained through that active, communal support, rather than through the exclusion of learners. (Postgraduate, female, age 25)

Another respondent (postgraduate, male, age 40) used the term 'community of practice' to describe activity around the journal, including Facebook group discussions, noting that such communities are particularly important 'when working in game studies where the field is still evolving and changing rapidly'. The use of such a term is interesting, as it evokes Lave and Wenger's (1991) work on situated learning and acknowledges that students learn from one another by sharing their knowledge and experience. As Dubé, Bourhis, and Jacob (2005) note, 'virtual communities of practice' use information and communication technologies (ICT) 'to allow their members to be creative and exchange what can sometimes be crucial pieces of information, in a virtual environment'. Such exchange is certainly taking place - and is valued - within the Press Start community, primarily in the associated Facebook group ('[the Facebook] group allows like-minded individuals to network and share ideas' - postgraduate, female, age 42) and via the journal's online review system. Beyond academia, too, it has been observed that near-scholarly communities of practice may readily evolve around games, for example, in the form of wikis (Barr 2014). The journal community was also described as 'a space to discuss' (postgraduate, female, age 24) and a 'safe space' in that: 'I viewed Press Start as an opportunity to publish early-stage research without feeling intimidated to do so' (postgraduate, male, age 23). 


\section{Barr}

One respondent referred directly to the scheme that sees games development students paired with students who are more confident in their writing: 'I really value the initiatives you have been putting forward for getting design students in contact with other academics for co-production' (postgraduate, female, age 42). Such initiatives rely upon - and ultimately seek to manipulate - the community of practice that has grown up around the journal, reflecting the fact that participants share an interest in the academic study of games while acknowledging that the community is simultaneously diverse in terms of its members' specific skills and interests. Game studies is a multidisciplinary endeavour, and this diversity is also reflected in the survey of the Press Start community, which comprises students from the arts, humanities, sciences, social sciences and applied sciences (see Figure 3).

Finally, supporting the assertion that aspiring games scholars can feel isolated, some respondents simply valued knowing that such a community existed at all: 'Knowing that there are actually people out there studying this sort of thing!' (graduate, female, age 40); 'Video game scholarship!' (postgraduate, female, age 24).

\section{Inclusiveness and accessibility}

The notions closely related to the idea of the journal as a supportive community are inclusiveness and accessibility, which also emerged from the survey data. One respondent (postgraduate, male, age 30) stated simply that what they valued about the journal was its 'Inclusivity, Positive Attitude'. A similar idea is encapsulated in the following response: 'I like that this journal gives voice to those who are just getting to the conversation' (postgraduate, male, age 30).

The diversity of aspiring games scholars is also touched upon in the data. For example: 'The inclusiveness and willingness to work across the wide variety of

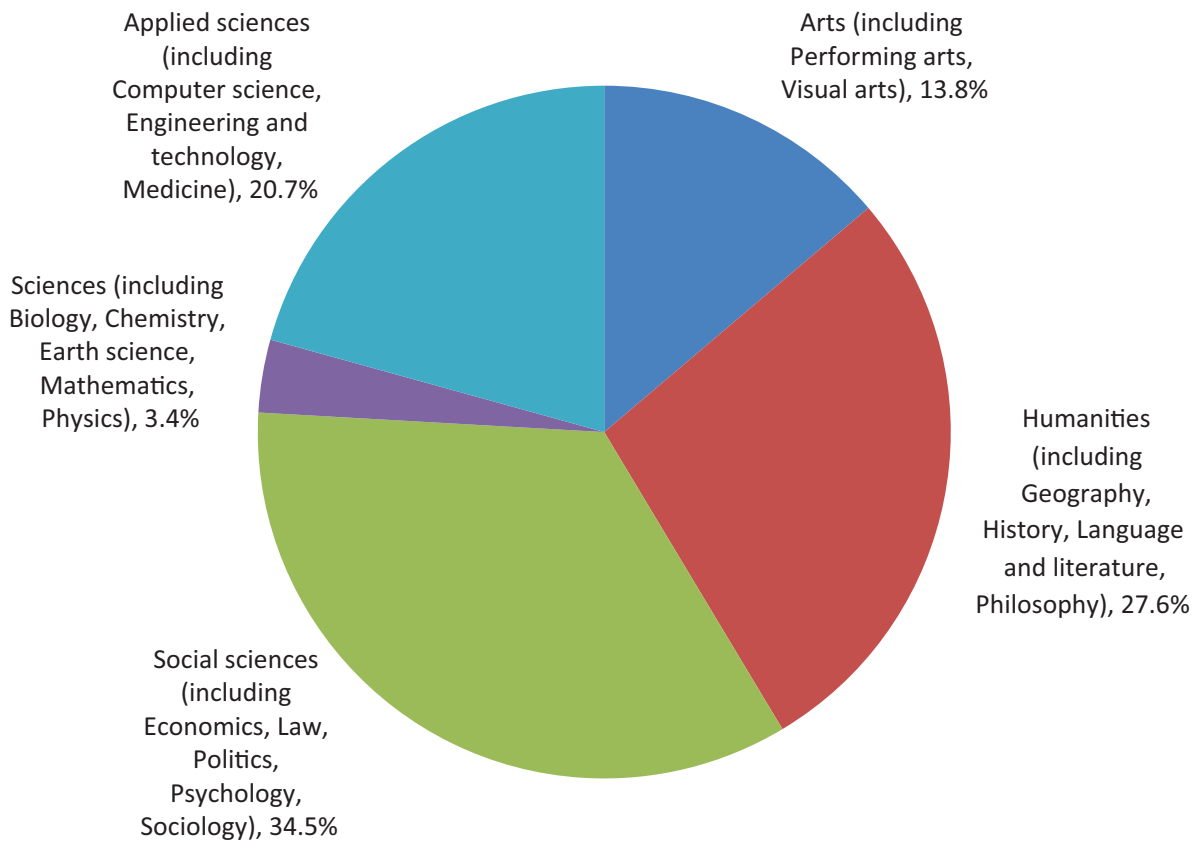

Figure 3. Disciplines in which survey respondents are situated. 
scholarship in games studies (i.e.: [Press Start] is not restricted to computer-science or design)' (postgraduate, female, age 26). Indeed, as Mäyrä (2008, p. 162) notes, 'the main emphasis in game design is on producing games rather than research papers' and, thus, the literature is dominated by work grounded in the humanities and social sciences. There are, therefore, few opportunities for game design and development students to publish academic accounts of their work, even in more established game studies journals and conferences.

\section{The published research}

In light of inferences that student journals are not 'real' journals, as per Gilbert's implication, it is interesting to note that one of the themes to emerge from the survey data related to the value placed on the work published in Press Start. Several respondents stated that they valued the research published in the journal above all else. For example, one respondent (undergraduate, female, age 22) stated simply that 'I have found great use in the papers', while another (undergraduate, male, age 24) valued '[t] he amount of information we can find in the published articles'. Others mentioned the journal content in addition to other valuable aspects, for example: 'It is an interesting publication about game studies' (postgraduate, male, age 28).

Indeed, Google Scholar data ${ }^{5}$ indicate that other academics have begun citing student work published in Press Start, suggesting that the research is of sufficient quality to be cited alongside that published in the so-called 'real' journals. Furthermore, the journal is indexed by a range of other services, including EBSCOhost and ProQuest, which position the published work next to that found in more mainstream publications.

\section{Learning from peer review}

Press Start was always intended to help develop students' writing by means of peer review so it is, perhaps, to be expected that this idea emerged from the data. Students valued two aspects of the peer review process: gaining feedback on their writing and personally engaging in peer review. These two aspects are discussed here separately.

\section{Feedback from peer review}

The importance of constructive peer review is stressed in all of the guidance issued to potential reviewers. As outlined above, three reviewers typically look at each submission, under the guidance of an editorial board member, and their reviews are compiled into a single meta-review. The sole purpose of this meta-review is to help authors improve their manuscript and reviewers take pride in providing detailed, thoughtful and practical feedback on received submissions. Cruel, dismissive or otherwise unhelpful feedback is not accepted. It is, therefore, encouraging to see that the quality of feedback offered through peer review is valued by students. For example:

It helps students get involved with the area they love and learn a lot through peer review. I am so thankful for having been able to publish and all the help and suggestions I got through peer review and the Facebook group. (Postgraduate, female, age 29).

${ }^{5}$ Press Start on Google Scholar: https://scholar.google.co.uk/scholar?as_publication=Press+Start 


\section{Barr}

Perhaps related to the quality of the feedback is the relative speed at which it is delivered: 'accessible, helpful and quick publication for starting/early researchers' (postgraduate, male, age 29). However, for students unfamiliar with the often less immediate nature of peer review in the wider academic world, receiving an editorial decision and detailed feedback within 6 weeks may not seem particularly impressive. The detailed nature of the feedback does appear to be valued, however, as this pair of quotes illustrates:

...the reviewing process operates smoothly and leaves a great deal of room for constructive feedback which is greatly valued. (Postgraduate, female, age 26)

[I] really like the in-depth review process and the detailed nature of the feedback on drafts. (Postgraduate, male, age 26)

The quality of the peer review process may be seen as an extension of the supportive community, and some of the data presented under the 'Community and support' section above are relevant here. Another participant makes an explicit link between the formal peer review process and informal feedback received via the wider community.

\section{Experience of conducting peer review}

The opportunity to 'be a reviewer' has already been mentioned in relation to being part of a community of practice. However, some respondents focussed on this aspect specifically: '[It] give[s] you the chance to collaborate in the reviewing process' (postgraduate, male, age 28); 'I love that it is a journal for game studies where students can publish or participate as a reviewer' (postgraduate, female, age 29). Respondents also valued being given the opportunity to see 'behind the curtain', perhaps demystifying the world of academic publishing and peer review. For example: 'Opportunity to experience the other side of university life (e.g., reviewing)' (graduate, male, age 28); 'Ability to see how a review process works for an academic journal' (graduate, female, age 29); and 'Good opportunity for students and recent graduates to familiarise themselves with academic writing and the publishing process' (postgraduate, female, age 42). In addition, one respondent also suggested that this experience may be useful beyond academia: 'From my perspective, it's an opportunity to fine tune research skills that could be applied in further study and in a professional environment' (postgraduate, male, age 28).

What is missing in these data, perhaps, is an insight into why the experience of peer review is valuable, beyond gaining insight into an otherwise opaque aspect of academia. Some possible factors with reference to the existing educational literature are discussed below.

\section{Opportunity to publish}

While the existence of a journal in which students may publish their games-related work has already been mentioned ('I love that it is a journal for game studies where students can publish...' - postgraduate, female, age 29), this aspect was not as widely valued as the supportive nature of the community or benefits of peer review. One respondent (postgraduate, female, age 25) referred directly to publication, stating that 
'Press Start is a great opportunity for students to be published', but aside from another postgraduate's previously considered mention of 'quick publication for starting/early researchers', the opportunity to publish was not what respondents valued most highly. However, bearing in mind the open nature of the question, it is clear that publication is important to at least some of the students involved with the journal. Furthermore, the results of the subsequent survey used to verify these findings placed greater emphasis on the opportunity to publish, as discussed in the section that follows.

\section{Triangulation of findings}

As noted above, an attempt was made to triangulate qualitative survey findings obtained from content analysis of the main survey data. The triangulation took the form of a simple survey, wherein members of the online community were asked to indicate which of the aspects identified above were valuable. The results are shown in Figure 4.

As indicated in the graph, none of the themes identified in the qualitative analysis were entirely rejected by the community, but there are some contradictions here. Most striking, perhaps, is the discrepancy between the strong evidence for the importance of the community and associated support found in the main survey and the relatively small proportion of respondents $(43.5 \%)$ that selected this option in the subsequent survey. The importance placed on the opportunity to publish is much less significant in the original qualitative data than the subsequent survey responses. However, the inclusiveness and accessibility of the journal, which also featured prominently in the initial qualitative data, is somewhat more strongly supported by the subsequent survey, with $52.2 \%$ of respondents selecting this option. Arguably the strongest agreement between the data sets is related to learning from peer feedback, which, when considered in terms of both conducting and receiving peer review, was perceived as

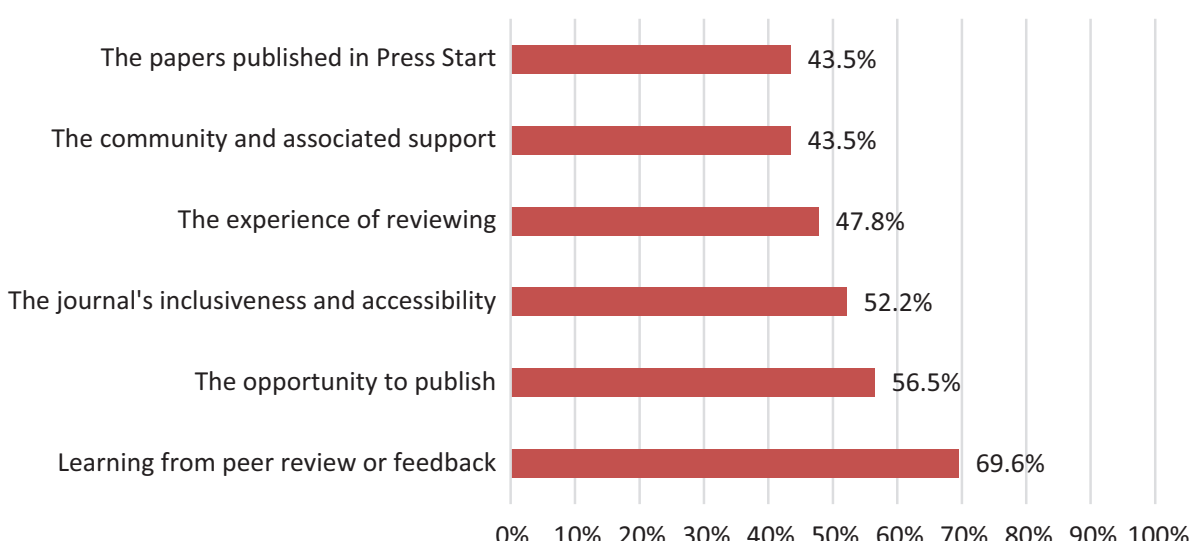

Figure 4. Results of data triangulation survey, showing the percentage of respondents $(n=23)$ who selected each option relating to what they valued about Press Start. Represents a 5.5\% response rate based on Facebook group membership of 392. 


\section{Barr}

highly valued in the initial qualitative data and is most prominent in the subsequent survey results.

\section{Discussion}

The results of the triangulation are somewhat varied. In some respects, this variability may be ascribed to the approach taken, wherein both data and method were triangulated. In terms of method triangulation, the use of a multiple-choice survey to verify data collected by means of an open-ended question appears logical, but the approaches are notably different. The former approach does not require the respondents to independently consider what they value about the phenomena in question, responding instead to a list of predefined options, some of which they may not have previously considered. Perhaps a better approach might have been to conduct more methodologically similar interviews with members of the journal community, thus relying more heavily on data triangulation. Another potential limitation of the approach taken was the omission of an 'other' or 'none of the above' option in the subsequent survey, which might have captured themes not identified by the initial qualitative analysis. With these limitations in mind, the findings may be discussed in greater detail.

While the peer review process is open to criticism, it may, when carried out responsibly, provide authors with 'good data about potential readers of their articles' (Starbuck 2003). The Press Start online community appears to view peer review in such terms, and this finding reflects the excellent work that our student reviewers produce. Indeed, Haaga (1993) found that students' peer reviews showed higher interrater reliability than 'professional' peer reviews of journal manuscripts; therefore, it is perhaps not surprising that this journal's enthusiastic and engaged student community is capable of producing high-quality peer feedback.

Haaga (1993) also observed that the student peer review process not only helped raise the quality of the reviewed papers but also provided students with an opportunity to 'learn to give constructive, substantive feedback to colleagues'. This relates directly to the finding here that students value the experience of conducting peer review and offers some insight into why they place such value on the experience. Through peer review, students involved in the online journal are provided with an opportunity not only to develop critical skills but also to reflect on their own writing and, perhaps, on the nature of the feedback they would value, personally.

Respondents also indicated that they valued receiving feedback via Press Start, which is perhaps not surprising. Rowe (2011) lists seven predominant reasons for students placing value on feedback, highlighting the interpersonal aspects of such interaction:

1. As a guide towards success in the course being assessed

2. As a learning tool

3. As a means of academic interaction

4. As a form of encouragement

5. As an emotion regulator and means of reducing anxiety

6. As an indication of respect

7. As a sign of caring 
Taking this more holistic view of the value of feedback, it becomes clear why Press Start authors are positive about this aspect of their experience: here feedback extends beyond mere assessment and is embraced as a learning tool, reflecting the ethos of a student-led journal. The supportive community that is evident in the collected data is also relevant here, in that the wider community - including peer reviewers, and also the editorial board and fellow members of the Facebook group - is apt to encourage, respect and care for one another. Furthermore, while it may be taken for granted that feedback is valued by students - or, indeed, any author - this assumption does not hold for feedback that is unhelpful. Weaver (2007), for example, found that students do value feedback but that this value was diminished by comments which were too general or vague, lacked guidance, focused on the negative or were unrelated to assessment criteria.

If there is one argument against providing authors with detailed, timely and helpful feedback via the Press Start peer review process, it might be that this does not prepare students for the real world of academia. This is a cynical point of view, however, which precludes the notion that feedback received from peers reviewing for more established journals may be as detailed and helpful. A more optimistic stance might be to suggest that their Press Start experience might raise not only students' expectations of peer review but also their aims in terms of the quality of peer review they will contribute to journals in the future.

It is clear that the students involved in this journal do not possess a cynical perspective with regard to peer review. Furthermore, the qualitative data presented here suggest that the student community sees value in the journal's peer review process that extends beyond validating the quality of published research, recalling, to varying degrees, the five roles that Schaffner (1994) suggested journals play in academic communities. One of these roles, which is clearly illustrated in the data presented here, is that of 'building scientific communities'. Press Start is certainly fulfilling this role, albeit, perhaps more in terms of how the Facebook group functions as an extension of the journal. Schaffner also discusses journals being used to 'distribute the awards', referring to the credit that is nominally associated with publishing new ideas, the value of which is assured by the fact that published work has undergone peer review. This role most closely relates to student responses that refer to the opportunity to publish, but might also be bound up in the value placed on the peer review process which, in turn, is believed to be important in ensuring the high quality of published papers.

\section{Conclusion}

Online journals have the potential to include students from across the globe and to act as catalysts for diverse online communities. Students value such communities and appreciate an inclusive approach to academic publishing. As such, establishing a student journal that is international in its outlook and engagement capitalises on the affordances of online journal software and associated social media. To limit membership of online journal communities based on geography or the level of study would be at odds with the inclusive ethos of the journal described here - an ethos that the presented data suggest is significant to students. Furthermore, removing artificial barriers to entry helps ensure that the community supporting the journal is drawn from a sufficiently large and sustainable pool of students. Unless there are 


\section{Barr}

sound pedagogical reasons for doing so - for example, where a journal is used to facilitate formal assessment - online student journals should embrace the opportunity to create larger, more diverse communities by welcoming students from beyond the host institution.

As evidenced by the fact that Press Start has operated continuously for more than 3 years, students are capable of running such a journal. Crucially, as the evidence presented here demonstrates, the students involved in the journal are also capable of providing timely, detailed and useful peer feedback on submitted manuscripts. Thus, by empowering students to manage all aspects of the journal, pressures on faculty may be substantially reduced without sacrificing the quality of the peer review process.

Student journals may be viewed as 'real' journals on the basis of the quality of the work they publish, and, by ensuring that work is readily discoverable online, there is no need to assume that a student journal is aimed solely as those not yet ready for 'prime time'. Certainly, the data presented here suggest that the published work is valued by the student community. Finally, a supportive, student-led community - such as the one described here - helps ensure that appropriate emphasis is placed on the opportunity to learn, rather than the pressure to publish. The data presented here reveal the emphasis placed on learning from involvement in both sides of the peer review process.

On the basis of the qualitative evidence presented here, it may be argued that the benefits of running an online student journal do outweigh the disadvantages identified above, at least from the perspective of students engaged in the endeavour. For educators and other practitioners, the implication of this suggestion is that the possibility of establishing an online international student journal should not be discounted on the assumption that the costs in terms of staff effort are prohibitive. Framed as a form of learning technology and with operational responsibility placed firmly in the hands of students, an online journal can offer educators a cost-effective means of enhancing the student experience.

\section{References}

Barr, M. (2014) 'Learning through collaboration: video game wikis', International Journal of Social Media and Interactive Learning Environments, vol. 2, no. 2, pp. 119-133. https://doi. org/10.1504/IJSMILE.2014.063385

Bauer, M. (2000) 'Classical content analysis: a review', in Qualitative Researching with Text, Image and Sound: A Practical Handbook, eds M. W. Bauer \& G. Gaskell, SAGE, London, pp. 131-151.

Budapest Open Access Initiative. (2012) Ten Years on from the Budapest Open Access Initiative: Setting the Default to Open. Available at: http://www.budapestopenaccessinitiative.org/ boai-10-recommendations

Caprio, M. J. (2014) 'Student publishing: future scholars as change agents', OCLC Systems \& Services: International Digital Library Perspectives, vol. 30, no. 3, pp. 144-157. https://doi. org/10.1108/OCLC-01-2014-0003

Charlesworth, S. M. \& Foster, I. D. L. (1996) "Water and environmental systems": achieving student-centred learning objectives with an undergraduate journal', Journal of Geography in Higher Education, vol. 20, no. 1, pp. 45-54. https://doi. org/10.1080/03098269608709344

Dubé, L., Bourhis, A. \& Jacob, R. (2005) 'The impact of structuring characteristics on the launching of virtual communities of practice', Journal of Organizational Change Management, vol. 18, no. 2, pp. 145-166. https://doi.org/10.1108/09534810510589570 
Gilbert, S. F. (2004) 'Points of view: Should students be encouraged to publish their research in student-run publications?: A case against undergraduate-only journal publications', Cell Biology Education, vol. 3, no. 1, p. 22. https://doi.org/10.1187/cbe. 04-01-0023

Haaga, D. A. F. (1993) 'Peer review of term papers in graduate psychology courses', Teaching of Psychology, vol. 20, no. 1, pp. 28-32. https://doi.org/10.1207/s15328023top2001_5

Hurkett, C., Raine, D. \& Roy, M. (2014) 'Undergraduate E-journals', Presented at the HEA STEM Annual Conference 2014, Higher Education Academy, Edinburgh, Scotland, [online] Available at: https://www.heacademy.ac.uk/resources/detail/stem-conference-2014/ Post_event_resources/Physical_sciences/Undergraduate_E

Kuper, A., Lingard, L. \& Levinson, W. (2008) 'Critically appraising qualitative research', BMJ, vol. 337, p. a1035. https://doi.org/10.1136/bmj.a1035

Lambert, C., \& Metcalfe, D. (2009). Editorial: The Importance of Great Expectations. Reinvention: An International Journal of Undergraduate Research, 2(1). Retrieved from https://www2.warwick.ac.uk/fac/cross_fac/iat1/reinvention/issues/volume2issue1/editorial

Lave, J. \& Wenger, E. (1991) Situated Learning: Legitimate Peripheral Participation (Learning in Doing: Social, Cognitive and Computational Perspectives), Cambridge, England.

Mariani, M., et al., (2013) 'Promoting student learning and scholarship through undergraduate research journals', PS: Political Science \&amp; Politics, vol. 46, no. 4, pp. 830-835. https:// doi.org/10.1017/S1049096513001133

Marvasti, A. (2004) Qualitative Research in Sociology, Sage Publications Ltd., [online] Available at: https://uk.sagepub.com/en-gb/eur/qualitative-research-in-sociology/book224943

Rowe, A. (2011) 'The personal dimension in teaching: why students value feedback', International Journal of Educational Management, vol. 25, no. 4, pp. 343-360. https://doi. org/10.1108/09513541111136630

Santiago-Delefosse, M., et al., (2016) 'Quality of qualitative research in the health sciences: analysis of the common criteria present in 58 assessment guidelines by expert users', Social Science \& Medicine, vol. 148, pp. 142-151. https://doi.org/10.1016/j.socscimed.2015.11.007

Schaffner, A. C. (1994) 'The future of scientific journals: lessons from the past', Information Technology and Libraries, vol. 13, no. 4, pp. 239-247.

Schofield, C., \& Burton, F. 1. (2015). An investigation into higher education student and lecturer views on research publication and their interest in the production of a college partnership science journal. Innovations in Education and Teaching International, 52(3), $265 \tilde{n} 276$. https://doi.org/10.1080/14703297.2013.808405

Showers, R. (2017, March 3). 2017 Social Media Demographics: What You Need to Know. Retrieved October 23, 2017, from https://www.tracx.com/resources/blog/ social-media-demographics-2017-marketers/

Starbuck, W. H. (2003) 'Turning lemons into lemonade: where is the value in peer reviews?', Journal of Management Inquiry, vol. 12, no. 4, pp. 344-351. https://doi. org/10.1177/1056492603258972

Stone, G., Jensen, K. \& Beech, M. (2016) 'Publishing undergraduate research: linking teaching and research through a dedicated peer-reviewed open access journal', Journal of Scholarly Publishing, vol. 47, no. 2, pp. 147-170. https://doi.org/10.3138/jsp.47.2.147

Twining, P., et al., (2017) 'Some guidance on conducting and reporting qualitative studies', Computers \& Education, vol. 106, pp. A1-A9. https://doi.org/10.1016/j.compedu.2016.12.002

Walkington, H. (2014) 'GEOverse: an undergraduate research journal: research dissemination within and beyond the curriculum', in Geoscience Research and Education, ed V. C. H. Tong, vol. 20, Springer, Dordrecht, Netherlands, pp. 189-197. https://doi. org/10.1007/978-94-007-6946-5_14

Walkington, H. \& Jenkins, A. (2008) 'Embedding undergraduate research publication in the student learning experience: ten suggested strategies', Brookes E-Journal of Learning and Teaching, vol. 2, no. 2, [online] Available at: http://bejlt.brookes.ac.uk/article/ embedding_undergraduate_research_publication_in_the_student_learning_experi/ 


\section{Barr}

Waye, L., \& Simpson, A. (2016). Reflections on a Student Research Journal: What are the impacts, and are they worth it? Transformative Dialogues: Teaching and Learning Journal, 9(2).

Weaver, M. R. (2007) 'Do students value feedback? Student perceptions of tutors' written responses', Assessment \& Evaluation in Higher Education, vol. 31, no. (3), 379-394. https:// doi.org/10.1080/02602930500353061 